\title{
DESDE LA RETÓRICA A LA INTERCULTURALIDAD. ALGUNAS REFLEXIONES DESDE LAS APORTACIONES DE BARTOLOMÉ DE LAS CASAS
}

\author{
LORENA ZUCHEL \\ Universidad Técnica Federico Santa María, Chile \\ IWONA KRUPECKA \\ Universidad de Gdańsk, Polonia
}

\begin{abstract}
RESUMEN: Optando por la retórica, Las Casas busca un modelo antropológico nuevo, distinto tanto del humanismo elitista, como del erasmismo voluntarista. En esta búsqueda quisiéramos poner énfasis, argumentando a favor de un resultado revolucionario a la luz de sus objetivos prácticos: cesar el homicidio y garantizar la libertad a los indios en cada aspecto de su vida. Desde aquí, nos referiremos a esta postura revolucionaria que bebe de Aristóteles y de santo Tomás, pero que es capaz de superarlos, a favor de una defensa de lo propiamente humano, que estriba precisamente en reconocer que todas las comunidades tienen la posibilidad de realizarse autónomamente. Por esto, creemos que se puede hallar, en Bartolomé de las Casas, una importante contribución a la cuestión del reconocimiento, pero aún más, un importante punto de partida para los desafíos de una filosofía intercultural.

PALABRAS CLAVES: Bartolomé de las Casas; retórica; interculturalidad; humanismo; reconocimiento.

\section{From Rhetoric to Interculturality. Some reflections on the contributions of Bartolomé de las Casas}

ABSTRACT: Writing in favor of the rhetoric, Las Casas was actually searching for a new anthropological model that would be different both from the elite humanism and from the Erasmian voluntarism. We would like to emphasize this attitude in the light of Las Casas' practical objectives, which is to prevent from further homicide and to guarantee an unconditioned freedom to the Indians in every aspect of their social life. We will refer to this revolutionary attitude which is based on the theories of Aristotle and St. Thomas, but is also capable of overshadowing them in defense of the humanity itself and human values. The most important point of Las Casas' theory is the recognition of the right and ability of every community to have an autonomous way of governing. For that reason, we argue, his writings can be interpreted as an important contribution to the question of the recognition of the Other, and as the theoretical starting point for the intercultural philosophy as well.

KEY WORDS: Bartolomé de las Casas; rhetoric; interculturality; humanism; recognition.

\section{INTRODUCCIÓN}

"¿Con qué derecho y con qué justicia tenéis en tan cruel y horrible servidumbre a estos indios? ¿Con qué autoridad habéis hecho tan detestables guerras a estas gentes que estaban en sus tierras mansas y pacíficas, donde tan infinitas de ellas, con muertes y estragos nunca oídos, habéis consumido?»

Sermón de Montesinos, 1511. 
Aquello que se ha llamado «descubrimiento» e «invención» de América tuvo lugar en pleno Renacimiento y, por supuesto, se inscribió en diversos debates del ámbito de la filosofía, teología y studia humanitatis ${ }^{1}$. La famosa discusión entre los escolásticos y los humanistas sobre la función de la retórica y, en general, de las ciencias humanas en el discurso filosófico y teológico, fue uno de los momentos más importantes en el proceso de cristalización del nuevo movimiento, es decir, de la actitud humanista. Es cierto que no se puede aseverar con unanimidad sobre los rasgos comunes de estos nuevos filósofos, pero probablemente una de las mejores caracterizaciones de los cambios renacentistas pueda encontrarse en los escritos de Stefan Swieżawski, quien bajo el término de "giro antidialéctico» trató de captar las similitudes entre varios representantes del nuevo método del pensar, tanto los herederos de los Calculatores de Oxford, como los humanistas platónicos italianos o los continuadores del devotio moderna (como Erasmo por una parte y Lutero por otra) ${ }^{2}$.

El tema de la rétorica y sus posibles aplicaciones, fuera de la filología pura, tuvo, pues, en los tiempos de la Colonia, larga historia y dedicación, pues palpaba directamente al problema de la divulgación y naturaleza de la fe cristiana, como lo muestra, por ejemplo, Ciceronianus, de Erasmo de Rotterdam, o la respuesta de Melanchton a la discusión entre Hermolao Barbaro y Pico Della Mirandola ${ }^{3}$. Pero al mismo tiempo - y como queremos demostrar en este artículo- en el pensamiento de Bartolomé de Las Casas se desarrolla una perspectiva nueva de la retórica como un primer paso para la constitución del — tan estudiado en Latinoaméricareconocimiento, cuestión que nos aproxima al concepto de Interculturalidad; derivando las implicaciones radicales de la función de la retórica, de por aquel entonces, en la estructura de la moralidad social de cualquier comunidad humana.

No obstante, quisiéramos anotar aquí que con todo lo insurrecta que pudieran parecer las acciones de algunos humanistas, a favor del reconocimiento de los indios de América, no puede dejar de enmarcarse dentro de un talante eurocéntrico, que desde entonces ha quedado impregnado fuertemente en las ideas políticas y filosóficas de América Latina, a través de las lecturas de una «filosofía de la Conquista», como lo delata Silvio Zabala en $1947^{4}$, entre otros; pues se trataría de una disputa entre europeos ${ }^{5}$, sobre sus propias validaciones, sobre sus propios

\footnotetext{
1 Cfr. O' Gorman, E. (1958), La invención de América. El Universalismo de la Cultura de Occidente, México-Buenos Aires

2 Cfr. SwIEżawsKi, S. (2002), Między średniowieczem a czasami nowymi. Sylwetki myślicieli XV wieku, Biblioteka Wiezi, Warszawa, p. 20.

3 Véase las explicaciones del conflicto entre los humanistas y escolásticos en RummeL, E., «Et cum theologo bella poeta gerit. The Conflict between Humanists and Scholastics Revisited», The Sixteenth Century Journal, 1992, Vol. 23, No. 2, pp. 713-726; Perreiah, A., «Humanistic Critiques of Scholastic Dialectic», The Sixteenth Century Journal, 1982, Vol. 13, No. 3, pp. 3-22. Sobre la discusión entre Bárbaro y Pico véase p. ej. Breen, Quirinus, "Giovanni Pico de la Mirandola on the Conflict of Philosophy and Rhetoric», Journal of the History of Ideas, 1952, Vol. 13, No. 3, pp. 384-412; Sснмітт, Сн. B., "Perennial Philosophy: From Agostino Steuco to Leibniz», Jourmal of the

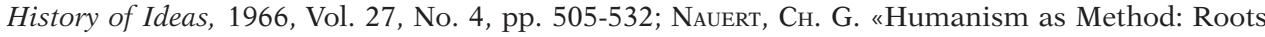
of Conflict with the Scholastics», The Sixteenth Century Journal 1998, Vol. 29, No. 2, pp. 427-438.

4 Zabala, S., Filosofía de la Conquista, México, FCE, 1994.

5 No es el caso de Bartolomé de las Casas, pero muchos de ellos jamás conocieron América, sino que construían sus argumentaciones sobre su humanidad desde ciertas noticias que recibían por los Conquistadores.
} 
intereses —como lo es la evangelización—, y entonces, con las impropiedades que se desprenden de estas mismas categorías. Con todo, este trabajo se dedicará a exhibir las fortalezas de las argumentaciones de Fray Bartolomé de las Casas, en defensa de los «indios» de América y de sus subjetividades, rescatando sobre todo su metodología. Se cree que en este contexto, las disputas de Bartolomé se vuelven revolucionarias, pues permiten comprender y aceptar, en el peor de los escenarios, acciones extrañas. Desde aquí, la fortaleza de estas argumentaciones, pero sobre todo, de este espíritu de «empatía moderna», se vuelve garante del «reconocimiento» de cualquier «otro» extraño.

\section{Bartolomé de las Casas y la Retórica. Gestación de una nueva manera de ENTENDER LO HUMANO}

Antes de entrar en lo que aquí nos convoca, es preciso, como lo ha mostrado Vidal Abril Castelló, y dado el momento crucial en la formación intelectual de Las Casas, que debamos reconocer la famosa controversia con Juan Ginés de Sepúlveda (1550/1551) y la elaboración de su versión escrita Tratados de 15526. La pregunta por la «modernidad $»^{7} \mathrm{y}$, al mismo tiempo, la importancia de la postura de Las Casas, resulta imposible de responder sin tomar en cuenta los pasajes dedicados allí al "modo de convencer», es decir, a la retórica, sobre todo porque revela lo específico de su punto de vista tanto contra Sepúlveda como, paradójicamente, contra la tradición erasmista.

Aunque en su disputa con Sepúlveda Las Casas no habla directamente sobre la retórica como tal, sino sobre el mejor modo de «convencer» o «convertir», sabemos que se refiere a la teoría ética de Aristóteles precisamente en el contexto de los juicios probables que constituyen el campo propio de la retórica. En la décima réplica aparecen las palabras que serán nuestra guía en las reflexiones siguientes:

«Y la razón por la cual debemos seguir los ejemplos de los virtuosos y buenos en el obrar o dejar de obrar, es porque los que son virtuosos y buenos son sabios en las cosas agibles y de costumbres (como más dirigidos y cercanos de la razón), la cual es regla rectísima de nuestras obras. Por esto dice el filósofo, $2^{\circ}$ de las Éticas, que el medio de la virtud es aquel que según los sabios determinaren. Y los sabios se entienden no según la razón especulativa, sino por la práctica, y por respecto de las cosas agibles. $\mathrm{Y}$ en el $6^{\circ}$ de aquella obra prueba que a los dichos y determinaciones de aquéllos, en la virtud, debemos sin otra prueba ni testimonio asentir o conceder, como asentimos a las demostraciones en las sciencias matemáticas». ${ }^{8}$

Estos «sabios», cuyo ejemplo debemos seguir, según Las Casas, son en realidad, como lo define Aristóteles y subraya el dominico, los hombres prudentes, es decir,

6 Cfr. AbRil CASTelló, V. (1984), «La bipolarización Sepúlveda-Las Casas y sus consecuencias: la revolución de la duodécima réplica», en Ramos, D., La ética en la conquista de América. Francisco de Vitoria y la Escuela de Salamanca, Consejo Superior de Investigaciones científicas, Madrid, pp. 229-288.

7 Puesta de nuevo p.ej. por Fernández Buey, F., «La controversia entre Ginés de Sepúlveda y Bartolomé de Las Casas. Una revisión», Boletín Americanista 1992-1993, núm. 42-43, pp. 303-305.

8 De las CaSas, B. (1992), Controversia entre Las Casas y Sepúlveda, en Obras completas 10: Tratados de 1552, ed. Hernández. R. y Galmés, L., Madrid, p. 171. 
no los que se especializan en las ciencias especulativas, sino los representantes de la sabiduría práctica, vinculada a las costumbres y tradiciones de las comunidades determinadas. Dos veces en este corto pasaje Las Casas repite el término «las cosas agibles», entendiéndolas como algo que es posible de hacer en dos sentidos: de lo que no es necesario (en la dimensión ontológica, que pertenece a la esfera de la libertad humana) y de lo que es posible de hacer desde el punto de vista de una determinada comunidad, es decir, posible de ser imaginado como algo que uno de sus ciudadanos pueda hacer. Esta doble perspectiva revela la verdadera función de autoridad de Aristóteles en la argumentación de Las Casas. Y en la misma réplica 10 el dominico deriva de dicha autoridad, directamente, la tesis sobre el modo de convertir a los infieles, poniendo como ejemplo a Cristo y a sus apóstoles. Es en la réplica 11 donde propone una resolución que podríamos llamar intercultural, y por eso opuesta tanto a la de Sepúlveda como a la de Erasmo.

El pasaje más revolucionario de la réplica 11 es en el que Las Casas introduce la categoría tomista de la sindéresis y la relaciona con la frónesis aristotélica, demostrando que la moralidad no es sino la esfera de la probabilidad. Puede parecer que esta constatación no trae novedad alguna respecto al concepto tradicional de la prudencia ${ }^{9}$, pero si la reflexionamos junto con la objeción de Sepúlveda, encontraremos que Las Casas sobrepasa, en este momento, la perspectiva paternalista y elitista, para llegar al punto de abrirse a la otredad ${ }^{10}$. Veamos.

La polémica central concierne al problema de justificar o no justificar los sacrificios humanos por una falta probable de los infieles, y de su conciencia errónea, que, según la doctrina tomista, obliga tanto como la correcta, y de esta manera constriñe a los infieles a actuar contra la «verdadera» ley divina y contra la «recta razón». Lo importante es que tanto Las Casas, como Santo Tomás, debido a la sindéresis —un hábito innato de reconocer los principios del obrar, de la ley natural ${ }^{11}$ - creen que para cualquier ser humano o ser racional resulta imposible vivir sin reconocer la ley natural, aunque estos principios tengan un carácter más universal. Pero al mismo tiempo, Las Casas se aleja del tomismo ortodoxo, poniendo todo el énfasis en la razón práctica (y no en la sabiduría como la virtud de la razón teorética) y subrayando el aspecto de la probabilidad de cada ciencia moral $^{12}$. En este punto se enfrenta a Sepúlveda en el terreno que parecía privilegiar

\footnotetext{
9 En la Ética a Nicómaco [1142a] ARISTóteles escribe: «Es, pues, la prudencia contraria del hábito que se llama entendimiento, porque el entendimiento considera los principios, para los cuales no hay dar razón, y la prudencia considera las cosas singulares y últimas, las cuales no se comprenden por ciencia, sino por el sentido; no por el particular de cada cosa, sino por tal sentido cual es él con que en las artes matemáticas juzgamos que esta última figura es triángulo». (La Ética de Aristóteles, lib. VI, cáp. 8, trad. del griego y analizada por P. S. Abril, http://www. cervantesvirtual.com/servlet/SirveObras/12482398660132622976846/index.htm). [Revisado en junio de 2015].

10 Sobre la novedad del proyecto lascasiano véase la síntesis de Fernández BuEY, F., op. cit., págs. 333-344; cfr. Someda, H. (2005), Apología e historia. Estudios sobre fray Bartolomé de Las Casas, Editorial de la Pontificia Universidad Católica de Perú, Lima, pp. 40-45.

11 De Aquino, Tomás, Questiones disputatae. De veritate, q. 16, art. 1, http://www. corpusthomisticum.org/qdv15.html. [Revisado en junio de 2015].

12 P. ej. en la Apologética historia sumaria Las Casas escribe: «El fin de las virtudes morales es el bien humano, y este bien humano es vivir el hombre según razón cada uno, según el estado que tiene y según lo que pide y requiere aquel estado. El cual fin no lo ponen de nuevo los hombres,
} 
al humanista «conquistado por Italia» ${ }^{13}$ y al famoso traductor de la Política: en el térreno de la interpretación de Aristóteles. Las Casas escribe:

«Luego no se dice la opinión probable por respecto de las reglas de la razón impliciter, sino porque así parece y así lo usan y aprueban los que son estimados por más sabios y más prudentes en cualquiera nación» ${ }^{14}$.

Las palabras de Las Casas que habría que subrayar son éstas: «cualquiera nación», pues explica un poco antes, que:

«los tenidos por más sabios y más prudentes entre cualquiera gente y de quien los menores y populares son regidos y gobernados, puesto que en la verdad aquéllos yerran y no sean sabios ni prudentes por respecto de la recta razón, mayormente por respecto de la fe y ley divina» ${ }^{15}$.

Como sabemos del sumario de Domingo de Soto ${ }^{16}$, en su texto leído durante la primera sesión de la junta en Valladolid, Las Casas también se apoyaba en la autoridad de Aristóteles, citando los Tópicos y la Retórica y de esta manera refiriéndose, aunque implicite, al concepto del silogismo «dialéctico». En el primer libro de los Tópicos, Aristóteles presentaba este tipo del silogismo como propio del arte de la discusión y de convencer, y lo contrastaba con el utilizado en la filosofía y en la ciencia. La diferencia entre ellos se funda en el carácter de las premisas: mientras en la ciencia - que trata de alcanzar una descripción de cualquier aspecto del mundo, en términos generales, y por encontrar las cuatro causas (material, formal, final y eficiente) - las premisas deben ser verdaderas; en la vida civil, política y moral, el objeto del conocimiento y discusión no es general, sino singular, y como tal, no pertenece a la esfera de lo necesario, sino de lo probable. Por lo tanto, igualmente las premisas del silogismo "dialéctico» no son más que probables, es decir, "conformes a la opinión pública», y las constituyen las creencias aceptadas o por todos, por la mayoría, o por los filósofos, etc. ${ }^{17}$. El argumento de Las Casas - quien intencionalmente pone el problema de convertir a los indígenas, y justificar sus sacrificios humanos en categorías de convencimiento sobre lo más verosímil- se hace incluso más claro a la luz de otra constatación aristotélica: que nadie prudente hubiera aceptado una premisa tal que contenga una proposición

sino que el Hacedor de la naturaleza imprimió en nuestra razón práctica ciertos principios naturalmente claros, y notas que nadie puede ignorarlas por la lumbre que tiene cada uno en su ánimo, que es el entendimiento que llaman agente, si totalmente no es ligado en el uso de la razón, como en los niños y bobos y mentecaptos; y estos principios, así natos y claros, son los fines de las morales virtudes, son también los preceptos de la ley natural, contenidos todos en un hábito que llaman los teólogos sindéresis, impreso en nuestra mente, y aquélla es la centella de la lumbre del ya dicho entendimiento agente, como si estuviesen en un vaso de cristal o de vidrio muy transparente». De Las CaSas, B., Apologética historia sumaria, lib. III, cap. 40, Fundación el Libro Total, pp. 550-551.

http://www.ellibrototal.com/ltotal/?t=1\&d=4072_4167_1_1_4072. [Revisado en junio de 2015]. Sobre esta base teorética Las Casas edificó toda la estructira de la Apologética, demostrando la universalidad la las leyes naturales y la diversidad de sus concretizaciones.

13 Bataillon, M. (1966), Erasmo y España, trad. de A. Alatorre, México, p. 408.

14 De Las Casas, B., Controversia..., op. cit., p. 178.

15 Ídem.

16 Ibídem, p. 128.

17 Aristoteles, Tópicos, lib. 1, 1 (100b) 
rechazada por la mayoría de los ciudadanos, ni hubiera desbaratado una creencia evidente en su comuniadad ${ }^{18}$.

Desde este punto de vista Las Casas puede - y no vacila en hacerlo- demostrar que diversos ritos y reglas morales indigenas no se contraponen a la racionalidad práctica, puesto que por una parte surgen de la ley natural y de su conocimiento —dado a cada ser humano a través de la sindéresis ${ }^{19}$ - y por otra cumplen las condiciones del silogismo dialéctico, en el cual a las premisas no se exige más que una aceptación de la opinión pública. Luego en la conclusión del argumento escribe explicitamente: «estante la falsa estimación y error dicho y ligación de la consciencia, que son obligados a defender su Dios o sus dioses que tienen por verdadero Dios, y su religión ${ }^{20}$.

Podríamos decir que en la controversia entre Las Casas y Sepúlveda encontramos otra cara del debate renacentista sobre el «verdadero Aristóteles», esta vez - y parece que por primera vez- enfocado en la pregunta por el relativismo cultural de la categoría de los «hombres prudentes». En otras palabras, así como se estilaba en la filosofía del siglo XVI, podemos preguntar, ¿un hombre prudente es así respecto de la razón recta o respecto de las costumbres y reglas de su comunidad? La respuesta de Sepúlveda resulta tan evidente para los hombres de aquel entonces, como etnocéntrica para los de hoy día.

Para Sepúlveda, un humanista verdadero (con todas las consecuencias de esta postura), sólo se podría derivar desde la interpretación de Aristóteles; pues convenía con un ideal renacentista de educación y racionalidad. Por lo tanto en su objeción 11 escribió: «digo que el Filósofo no entiende por sabios ni prudentes a los menos bárbaros, sino a los que son entre las gentes políticas y humanas» ${ }^{21}$. Es decir, sólo los representantes de las comunidades reconocidas por no bárbaras - europeas, cristianas, "humanas» en el sentido más estricto, que excluye todos los que no cumplen las reglas sociales y culturales y caen bajo la quasi-medieval categoría de monstruos- pueden ser prudentes de verdad. Aquí mismo tocamos la ambigüedad inscrita ya en el pensamiento aristotélico: por una parte, Aristóteles introduce el concepto de esclavitud por naturaleza en su primer libro de la Política describiendo a los bárbaros como los que por la falta de razón no son capaces de llevar una vida política, es decir, constituir un estado por leyes y tradiciones y no por la fuerza ${ }^{22}$, pero por otra parte, en el tercer libro de la misma obra, describe las monarquías «bárbaras», distinguiéndolas de las formas tiránicas de gobierno, por subrayar la función de la ley y de la tradición, conservando y graduando al mismo

18 Ibídem, lib. I, 10 (104a).

19 Como lo hace en la Apologética. Como lo muestran LosadA, A. en «Observaciones sobre «La Apologia» de fray Bartolomé de Las Casas, respuesta a una consulta», Cuadernos Americanos, 1977, Vol. CCXII, nr 3, pp. 153-158; ZavaLA, S., «Aspectos formales de la controversia entre Sepúlveda y Las Casas, en Valladolid, a mediados del siglo XVI», Cuadernos Americanos, 1977, Vol. CCXII, nr 3, pp. 138-150; o Hanke, L., («Uno es todo el género humano. Estudio acerca de la querella que sobre la capacidad intelectual y religios de los indígenas americanos sostuvieron en 1550 Bartolomé de las Casas y Juan Ginés de Sepúlveda»), Chiapas-México 1974, págs. 79-81. Las Casas presenta alli «de facto» lo que antes había probado «de ius» en Apología o en controversia con Sepúlveda.

20 De Las Casas, B., Controversia..., op. cit., p. 177.

21 Ibídem, p. 145.

22 Aristóteles, Política, lib. I 2, 18 (1255 a), lib.. I 2,13 (1254 b). 
tiempo el nivel de la «barbariedad» entre los griegos, los europeos, los orientales, etc. ${ }^{23}$. Esta gradación de la inclinación natural a la esclavitud cobra importancia, porque demuestra que ya no hablamos de una diferencia cualitativa entre razonables e irrazonables, sin estados intermedios, sino más sobre una diferencia cuantitativa. Así los bárbaros, por ejemplo, pueden constituir y conservar una monarquía, aunque imperfecta ${ }^{24}$ o vivir políticamente e inclinados a algún tipo de tiranía. Debemos tener en cuenta que según Aristóteles ambos tipos del poder — tanto la república, como la monarquía o incluso tiranía- son naturales, y representan la supremación de lo espiritual sobre lo corporal. Si el alma ejerce su poder sobre el cuerpo, representa al poder despótico analógico sobre el poder del esclavo, si la razón gobierna a los deseos, lo hace al modo del gobierno republicano ${ }^{25}$. En ambos casos encontramos pues una dominación del alma. Nos podemos preguntar si esto significa que de la forma despótica de gobierno se puede derivar una característica de la irracionalidad. Pero parece que no - y aquí se nota esta ambigüedad que fue tan útil para Las Casas dentro del pensamiento aristotélico-, porque analizando las naciones asiáticas Aristóteles no vaciló en llamarlas listas, inteligentes y de mucha capacidad artística, y buscar la causa de la tiranía no en su irracionalidad, sino en la falta del coraje $\mathrm{e}^{26}$.

La interpretación sepulvediana de la Política y del concepto de esclavitud por naturaleza elimina todas las oscuridades del discurso aristotélico, para darle una explicación muy intuitiva para un humanista y un alumno de Pomponazzi. Del movimiento humanista, aunque muy relacionado con un programa de Leonardo Bruni de la formación de un "hombre nuevo», multidimensional y conciente de todos los componentes de lo humano, pocas veces surgían teorías igualitarias (uno de los ejemplos más significativos del igualitarismo humanista fue el programa de los erasmistas, y entre ellos, de la teoría pedagógica de Luis Vives). Al contrario, como lo muestran los ejemplos tanto de los platónicos (como Pico della Mirandola o Ficino), como de los aristotélicos, tanto de los «eruditas» (como Hermolao Barbaro), como de los «filósofos», muy a menudo ser «humano» significaba o ser un hombre de enseñanza del tipo humanista, o ser un hombre racional según las reglas de la philosophia perennis. Por lo tanto fuera del erasmismo con muchas dificultades encontramos un modelo igualitario que permitía abandonar un discurso paternalista tan típico para aquel entonces y para el discurso colonial.

Este paternalismo y elitismo es muy notable tanto en la postura de Sepúlveda como en la de Vitoria. Hay por lo menos dos denominadores comunes entre ellos en cuanto a nuestro tema: primero, ambos reconocen poca capacidad intelectual de los indios (aunque Vitoria lo constata del modo hipotético), y segundo, admitiendo esta premisa proponen una aculturación violenta en nombre del bien de los indios, a quienes conceptualizan a través de una comparación con niños o bestias, es decir, a través de elementos corporales ${ }^{27}$. Por lo tanto es necesario preguntar, ¿cómo ellos

23 Ibidem, lib. VII 6, 1 (1327 b).

24 Ibídem, lib. III 9,3 (1285 a).

25 Ibidem, lib. I 2, 11 (1254 b).

26 Ibidem, lib. VII 6, 1 (1327 b).

27 Sobre la red de las oposiciones con las cuales se pensaba sobre los indios véase sobre todo Todorov, T., La conquista de América. El problema del Otro, México 1998, pp. 164-165; también Rengifo Lozano, B. (2007), Naturaleza y etnocidio, pp. 48-66; Zavala, S. (1975), Servidumbre natural y libertad cristiana según los tratadistad españoles de los siglos XVI y XVII, ed. 2, México, pp. 14-15. 
definen la racionalidad? ¿Con qué términos la describen? O, mejor dicho, ¿qué les faltaría a los indios para ser racionales?

En uno de los pasajes finales de su famoso discurso De indis, Vitoria se refiere al título hipotéticamente legítimo de la guerra contra los indios: por su irracionalidad. El estado infantíl o servil de los indios se manifestará por la falta de una «legítima y ordenada república dentro de unos términos humanos y civiles», por la ausencia de «leyes convenientes [y] magistrados», por no saber "gobernar la propia familia», por carecer «de letras y de artes», y por míseros «alimentos» y costumbres casi bestiales $^{28}$. Desde la perspectiva de la filosofía y la cultura clásica, la racionalidad siempre tenía un único rostro: el que se describía en los términos de la cultura antigua griega o romana y después cristiana medieval, de manera que para Vitoria resultaba evidente la mezlca de la ley natural y divina, y «lo humano» o racional significaba lo conforme a las normas europeas de aquel entonces. Podríamos decir, que la palabra «cultura» aparecía sólo en singular. Por esto, nos podemos preguntar, ¿qué tienen de verdad las palabras como "convenientes», "humanos», «ordenado» etc.? Y responder con la famosa frase de Montaigne: "Lo que hay es que estas gentes no gastan calzones ni coletos ${ }^{29}$. Para Vitoria, a pesar de todo su humanismo, la Otredad quedaba incomprensible, porque dentro del aristotelismo o tomismo ortodoxos era imposible pensar las culturas en plural.

En Demócrates segundo esta tentación de universalizar el modelo europeo de la vida se manifiesta con aún más claridad. Introduciendo el concepto de la esclavitud por naturaleza. Sepúlveda escribe:

«el dominio no se ejerce siempre del mismo modo [...] y siendo éstos dominios tan diversos, sin embrago, cuando se apoyan en la recta razón, todos tienen su fundamento en el derecho natural, que dentro de su variedad, parte, como enseñan los filósofos, de un solo principio y dogma natural: el imperio y dominio de la perfección sobre la imperfección, de la fortaleza sobre la debilidad, de la virtud excelsa sobre el vicio» ${ }^{30}$.

En su larga polémica con Las Casas Sepúlveda subraya la función de la «recta razón», defendiendo este modelo monológico y excluyente de la racionalidad, transmitido de la filosofía clásica, y a la vez haciéndolo incluso más implacable. Deja al lado las sutilezas del pensamiento aristotélico, en el cual la gradación de la racionalidad en sus diversos aspectos todavía fue posible, y donde incluso los bárbaros asiáticos le aparecían listos, aunque cobardes. Pero Sepúlveda destaca la diferencia irreductible entre el ser humano — racional según las normas de la razón especulativa, de la enseñanza académica renacentista y del modelo aristotélico de la ciudadanía - y el ser corporal, animal o semi-animal, en diferencia que no permite gradación. En su tratado leemos:

28 De Vitoria, F. (1992), Doctrina sobre los indios, ed. de Ramón Hernández, Salamanca, pp. 146. Confrontar con el análisis excelente de ABRIL Castelló, V. Los derechos de las naciones según Bartolomé de Las Casas y la Escuela de Salamanca en: B. DE LAS CASAS, Obras completas, t. 6, Apologética historia sumaria 1, Madrid 1992, p. 142.

29 De Montaigne, M., De los caníbales, en: idem, Ensayos, ed. digital: http://bib.cervantesvirtual. com/servlet/SirveObras/01372719700248615644802/p0000002.htm\#I_36_. [Revisado en junio de 2015].

30 Ginés de Sepúlveda, J. (1997), Demócrates segundo, en Obras completas III, Pozo Blanco, p. 54. 
«Pues el hecho de que algunos de ellos parezcan tener ingenio para ciertas obras de artificio no es argumento de más humana prudencia, puesto que vemos cómo ciertos animalitos, como las abejas y las arañas, hacen obras que ninguna humana habilidad logra imitar. [...] pues para mí la mayor prueba que nos descubre la rudeza, barbarie e innata esclavitud de aquellas gentes son precisamente sus instituciones públicas, ya que casi todas son serviles y bárbaras. Pues el hecho de tener casas y algún modo racional de vida en común y el comercio a que induce la necesidad natural, ¿qué prueba sino que ellos no son osos o monos carentes por completo de razón?» ${ }^{31}$.

Esta argumentación de Sepúlveda se funda en un menosprecio de lo puramente práctico o técnico en nombre de la racionalidad especulativa, es decir, de la sabiduría de los filósofos, que saben descubrir tanto las causas últimas del mundo, como las últimas verdades sobre la realidad humana, social y política. Junto con lo especulativo, Sepúlveda privilegia la certeza sobre la probabilidad y, por lo tanto, la diálectica sobre la retórica. Pues en ningún momento se busca un espacio de diálogo o de interlocución entre partícipes de su auditorio, sino un método de enseñanza monológica, donde existe un maestro sabio y sus alumnos todavía vacíos de luz, incompletos en su humanidad. Aún más, aunque Sepúlveda, igual que Vitoria, presenta el estatus servil de los indios como temporal («mientras se hallasen en dicho estado», escribe el teólogo salmantino ${ }^{32}$ ), ninguno de ellos teoriza un posible estado final, en el cual los indios logren el nivel de racionalidad o enseñanza suficiente para liberarse.

En realidad, aquí tocamos otra paradoja, porque una oposición irreductible entre un ser humano/europeo/cristiano y uno bárbaro, que sirve para legitimizar la fuerza contra los indios, está desbaratada en el paso siguiente, también necesario en el discurso imperial, en el cual la empresa de colonización obtiene una cara de «misión» civilizadora. Ésta pues exige que dicha oposición sea reductible, es decir, que los indios sean capaces de pasar de un estado servil a un estado de hombres libres. Habrá que considerar también otra consecuencia de la postura «dialéctica». En el proceso pedagógico un alumno no constituye un ser humano completo, sino casi un entendimiento puro, capaz de alejarse del cuerpo y de la sociedad y disciplinar todos los apetitos naturales para obtener un punto de vista universal.

El énfasis puesto por Las Casas en «convencer» a los indios con los instrumentos retóricos podríamos pensar que proviene de la inspiración erasmista ${ }^{33}$. En su Del único modo de atraer a todos los pueblos a la verdadera religión escribe explicitamente sobre la necesidad de utilizar los métodos retóricos por los predicadores, refiriéndose a los principios de Cicero:

«El predicador o maestro que tiene el encargo de instruir y atraer a los hombres a la fe y religión verdaderas, debe estudiar la naturaleza y principios de la retórica, y debe observar diligentemente sus preceptos en la predicación, para conmover y atraer el ánimo de los oyentes, con no menor empeño que el retórico u

Ibídem, p. 67

32 De Vitoria, F., op. cit., p. 146.

33 Véase p. ej. D La Hoz, J. C. M., "Bartolomé de Las Casas y la “captatio benevolentiae”», Ciencia tomista, 2007, t. 134, núm. 433. 
orador que estudia este arte y observa en su oración sus preceptos, para conmover y llevar a sus oyentes al punto que se propone» ${ }^{34}$.

Su descripción de los métodos de convertir a los infieles está fundada en la teoría tomista del primado de la razón sobre la voluntad en los procesos cognoscitivos (Las Casas no acepta el voluntarismo erasmiano ni su idea de Deus absconditus, aunque reconoce el valor y la función de la libre voluntad en la fe, puesto que ésta significa un acto del querer a Dios, por lo tanto un acto de la voluntad, y no de la razón). Es el entendimiento el poder que presenta a la voluntad el objeto del deseo, de manera que en la predicación, conforme además con las reglas de Cicero, uno debe instruir, deleitar y conmover ${ }^{35}$, de ahí que primero el entendimiento pueda concebir e incluir las ideas nuevas al sístema del conocimiento anterior y después ofrezca a la voluntad este objeto como digno de desear («debe ser un modo que persuada al entendimiento y que atraiga, mueva o excite a la voluntad» ${ }^{36}$ ). Pero, ¿cuál es esta razón que le interesa a Las Casas? Aquí el punto de controversia con Sepúlveda se hace más notorio, porque para el dominico, en la esfera de la moralidad y religión es primordial la razón práctica, encubierta en el contexto social, histórico y accidental, aunque vinculada a la vez a ciertos principios universales del obrar, a través de la sindéresis. Cada uno —escribe Las Casas ya en el año 1526- se inclina naturalmente al bien (y ésta es la primera regla de la ley natural), pero como la determinación de este bien no depende directamente de la recta razón especulativa, sino de la razón práctica, siempre estará condicionada por las costumbres de una sociedad. En el parágrafo noveno Del único modo Las Casas sigue a Aristóteles, mostrando la fuerza de las costumbres, que son nuestra «segunda naturaleza», y dice:

«Lo que es familiar en fuerza de alguna costumbre, se oye con mayor gusto y con mayor facilidad se acepta; porque las cosas que nos son familiares, nos son agradables; y las cosas que no son agradables, se nos hacen agradables en virtud de la costumbre, como escribe el mismo Filósofo» ${ }^{37}$.

Como era de suponer, Las Casas casi elimina en este parágrafo el motivo de la verdad como tal o de la recta razón, enfocándose a la visión de las comunidades y de las costumbres que les asemeja a un medio natural, el cual no es posible sobrepasar sin muchísimas dificultades. En realidad, su argumentación por la importancia de las costumbres en moldear la conciencia humana por su primera premisa tiene la proposición aristotélica, que cosiste en que la ciencia, las costumbres o las leyes son un suplemento para las fuerzas naturales, y que cuando éstas ya no son suficientes, la razón y el arte imitan la naturaleza para «regular y conservar» la vida. La imitan — podemos añadir - también en este aspecto que constituye un ambiente insuperable y evidente para sus habitantes; es un complejo de normas que forman una estructura poco variable y — como si fueran mónadas de Leibniz- «de pocas ventanas». No sorprende pues que Las Casas no mencione

34 De Las Casas, B. (1975), Del único modo de atraer a todos los pueblos a la verdadera religión, advertencia preliminar de A. Millanes Carlo, introd. de Hanke, L., México, p. 94.

35 Ibidem, p. 96.

$36 \quad$ Ibidem, p. 99.

$37 \quad$ Ibidem, p. 129. 
la teoría aristotélica de la irracionalidad bárbara, porque si no establece otro punto de referencia universal que la sindéresis, ese inclinación natural al bien sin determinar este bien en detalle, la única racionalidad posible es ésta intrínseca a la estructura cultural de una comunidad y, además, del carácter práctico. A la luz de estas consideraciónes Las Casas puede también buscar las pruebas de la racionalidad de los indios, como lo hizo en su Apologética historia sumaria, no sólo comparando las instituciones públicas, leyes o letras indígenas con un modelo europeo, universalizado, identificándolo con la razón recta, sino sobre todo a través de la comparación de distintas prácticas; prácticas habituales, es decir, surgidas del mundo de vida de cada sociedad.

Los postulados lascasianos para apreciar las culturas paganas (a pesar de su evidente voluntad de pacificación y su modelo de buen cristiano) tienen su origen en el pensamiento de Erasmo, donde encontramos también una prefiguración de la famosa inversión de la barbariedad, expresada por Las Casas explícitamente durante la controversia con Sepúlveda. En Ratio verae theologiae Erasmo presenta su método de convertir, y por otro lado introduce la cuestión de la idolatría como un punto de partida para injertar la fe verdadera sobre un tronco de la divinidad falsa (entre otros temas típicos de su pensamiento). Refiriéndose al ejemplo de San Pablo con los Romanos, Erasmo destaca la posibilidad de tomar la imagen de cualquiera divinidad —en este caso del «Dios desconocido» de Atenas $^{38}$ — para rellenarla con un contenido nuevo, pero comprensible para los oyentes. Tanto San Pablo, como Erasmo, usan aquí la palabra griega $\sigma \varepsilon \beta \alpha ́ \sigma \mu \alpha \tau \alpha$, que significa objeto del culto religioso, y que, por ser tan general, puede contener tanto una imagen cristiana, como la pagana de un dios ${ }^{39}$. Erasmo interpreta este ejemplo conforme a su pacifismo y deriva una regla que podemos parafrasear así: si uno quiere "conquistar las almas», primero tiene que adaptarse a las normas, capacidades y afectos de los páganos y sólo después puede combinar las ideas nuevas con las anteriores ${ }^{40}$. Desde aquí pareciera que en la etapa de Del único modo Las Casas no se aleja mucho de la perspectiva erasmista, aunque también con una base tomista, e incluso, por la manera de leer a Aristóteles, se acerca también en su pensamiento tardío.

En el tiempo de su disputa con Sepúlveda Las Casas tiene ya una visión de las comunidades indígenas como verdaderamente humanas, es decir, ordenadas, politizadas, con sus propias tradiciones y modos de vivir. Modos de vivir que - habrá que puntualizar- pudieran ser conservados en su totalidad sin que esto cause la perdida del derecho de autonomía ${ }^{41}$. Optando por la retórica, Las Casas está buscando a la vez un modelo antropológico nuevo, distinto tanto del humanismo elitista, como del erasmismo voluntarista. Esta revolución parece necesaria a la luz de sus objetivos prácticos: cesar el homicidio y garantizar la libertad a los indios en cada aspecto de su vida. Por eso Las Casas no puede referirse al ideal humanista y erudito del orador, porque éste supone un oyente educado en letras, y consciente

38 Vase en de los Hechos de los Apóstoles 17, 16-34

39 Véase De Rotterdam, E., Ratio verae theologiae, LB 99 a, H 225.

40 Ibídem, LB 99a, B,

41 Véase sobre todo Friede, J. (1974), Bartolomé de Las Casas, precursor del anticolonialismo. Su lucha y su derrota, Siglo XXI, México. 
del arte retórico. Lo notamos, por ejemplo, en la famosa carta de Hermolao Bárbaro a Pico Della Mirandola, donde la oposición «bárbaro»/«humano» cumple el papel principal y obtiene un significado antiescolástico y antidialéctico, pero no igualitario, porque establece un nuevo tipo de elite: la de los hombres de letras. Bárbaro lo expresa explicitamente, diciendo que entre estos bárbaros hay que contar todos los autores escolásticos, que no disponen del estilo «elegante», simple y puro, aunque en sus textos revelaren algunas verdades eternas ${ }^{42}$. Por lo tanto el discurso de los humanistas-eruditos resulta inútil para Las Casas, de la misma manera que le es inútil la tradición paduana de la escuela de Pomponazzi, que reservaba los trucos retóricos para las masas humanas que no eran capaces de raciocinar filosóficamente, y a las cuales habría que disciplinar con el miedo y la visión del premio concreto. Así que en ambos casos la oposición entre los que son racionales y saben la verdad, y los que no la saben, estaba en juego.

Sin embargo, y quizá más interesante, es que Las Casas no acepta del todo el pensamiento de Erasmo, como no aprovecha su voluntarismo, que sería más conveniente en la argumentación contra los métodos violentos de la predicación. En lugar de esto, y como hemos visto aquí, se dedica a la reinterpretación de Aristóteles, Cicero y Santo Tomás, escogiendo de sus escritos estas proposiciones que hacen de la razón un poder primordial en el conocimiento y la vida humana.

Con todo, podemos arriesgar una hipótesis, que Las Casas reflexionó muy bien la cuestion del «dios desconocido» y en su pensamiento tardío derivó las consecuencias del reconocimiento de la existencia de una estructura universal probable de todas las culturas, que, teniendo este carácter más universal, haría posible tanto la diversidad de los modos de pensar y actuar — es decir, de varias prácticas - como una puerta de entrada al diálogo intercultural. Desde esta perspectiva, podríamos decir que Las Casas necesitaba a Santo Tomás para tomar un concepto de la sindéresis, este hábito innato de conocer intuitivamente la ley natural, las reglas universales del obrar, que están privadas del contenido concreto y cuyo ejemplo más significativo es la regla general «seguir el bien y evitar el mal». De esta manera Las Casas constituyó un espacio de diálogo posible, un punto de referencia común para todos los seres humanos, pues siguiendo su teoría, si todos comprendemos el bien como lo que vale la pena seguir, como lo que deseamos, podemos discutir, por ejemplo, sobre las causas de estos deseos y efectos de nuestros actos, podemos distinguir lo natural de lo naturalizado, comprender los mundos de vida, y la razón o realidad (abierta, histórica) de las distintas culturas. Este es un punto que no se encuentra en el voluntarismo de Erasmo, porque en sus escritos él subrayaba sobre todo la gracia divina y la transformación interna del alma, y en consecuencia, en vez del diálogo, un monólogo del gran Orador.

Por otro lado, necesitó a Aristóteles para demostrar que cada intento de rellenar estas reglas y conceptos universales estaba condicionado por el contexto social, y por eso no podía ser sino probable. Por lo tanto, cuando Las Casas privilegia la retórica como un método de predicación, no lo hace por razones académicas o puramente pedagógicas, sino porque no tiene otra posibilidad. Al reconocer la probabilidad de cada ciencia moral y revelar su naturaleza social, ya no puede concebir a un

42 Véase Breen, Q., op. cit., p. 393. 
individuo de otra manera que sólo como un elemento de una estructura cultural vista como determinante e insuperable. Desde aquí, el camino hacia la inversión de la barbaridad y hacia la pregunta por la validez del punto de vista europeo resulta precario.

\section{APORTACIONES Lascasianas PARA la InTERCUlturalidad}

Nos atrevemos a decir que hablar de Bartolomé de las Casas hoy es hablar de Interculturalidad. En efecto, diálogo, comunidad, universalidad, reconocimiento, son conceptos que ligan los esfuerzos de antaño, con los de hoy, en una sola misión: la práctica de un universalismo concreto, cuyo centro es la justicia ${ }^{43}$. Un claro ejemplo de esto es lo que Raimon Panikkar esbozara a principios del siglo XXI:

«En la cima del entusiasmo por haber "descubierto el Nuevo Mundo", los europeos, que se encontraron con culturas consideradas aberrantes (quizás para justificar de manera más o menos inconsciente la explotación de los indígenas), llegaron incluso a considerar plausible la hipótesis de que aquellos nativos no fuesen seres humanos dotados de alma. Por motivos análogos, en la cima del entusiasmo occidental por haber "descubierto la Nueva Tecnociencia" los "creyentes" entusiastas de hoy, aunque sea de buena fe, cuando entran en contacto con otras culturas que consideran primitivas o subdesarrolladas, llegan a creer que tales culturas no poseen alma (vida, futuro), razón por la cual podemos y debemos "convertirlas" a la "nuestra" que, a pesar de sus imperfecciones, "nos" ofrece el único paradigma posible» ${ }^{44}$.

Desde aquí, quisiéramos proponer un giro en esta exposición, con algunas reflexiones sobre aquellas cuestiones que harían del legado de Bartolomé de las Casas una formulación para nuestro tiempo. En efecto, así como hemos expresado en las páginas iniciales, las argumentaciones planteadas por estos filósofos renacentistas son parte importante de la historia de argumentaciones de la filosofía europea occidental, y por lo tanto, plantear un verdadero reconocimiento hacia los indios de América, desde el eurocentrismo reinante, parece ser un discurso que se contradice a sí mismo. El propio Bartolomé de las Casas es consciente de estas dificultades, y por eso es que apela a unas metodologías que hagan partícipe de la discusión a los propios protagonistas, no por clausurar temáticas, sino precisamente por abrirlas hacia otras comunidades, no tan sólo periféricas, sino también a comunidades de personas que no pertenecen a la elite, a los «eruditos».

Y entonces ¿qué significa esta apertura? Así como la podemos entender desde la interculturalidad, no se trata de asimilar simplemente la pluralidad interdiscursiva o incluso interdisciplinar, que ha ido caracterizando, por cierto, el decurso de la filosofía, desde el siglo VI a.C. en adelante. Pues, efectivamente, se puede reconocer que la misma historia de la filosofía ha ido conformándose como una sola razón, desde la variedad de planteamientos y tradiciones; pero si precisamente esta

43 Fornet-Betancourt, R. (2003), Interculturalidad y Filosofía en América Latina, Verlag Mainz (Concordia, serie Monográfica, 36), Aachen, p. 141

44 Panikkar, R. (2006), Paz e Interculturalidad. Una reflexión filosófica, Herder, Milán, p. 17. 
variedad es la que permite calificar como filosófica la historia de la filosofía, habrá que revisar críticamente los modos de participación y valor de los distintos sujetos en el curso de esta historia, pues la variedad de tradiciones, o como se atreve a decir Fornet-Betancourt, de filosofías, no son un mero adorno, sino mundos de interpretación desde donde se echan raíces ${ }^{45}$ y pronuncian los seres humanos, o incluso cada ser humano como — dicho roigianamente-a priori antropológico ${ }^{46}$.

Este concepto es sustancial para entender lo que aquí queremos comentar. Pues se trata de una noción que quiere abandonar la idea del sujeto universal abstracto, desvinculado de la facticidad social, y abrazarse a la practicidad del mismo - como el propio De las Casas insistía-, para que, desde allí, se abra a la comprensión del mundo, desde un «nosotros», como sujetos históricos, necesitantes de otra autoconciencia para efectuar el reconocimiento de manera radical, en cuanto se asume en el acto su historicidad relacional ${ }^{47}$. En este sentido, la autoafirmación fundante de los sujetos es autojustificación, o dicho de otro modo, es la puesta de uno mismo como justificante, pero ya no de una existencia egocéntrica, o de una "pasión inútil», dicho sartreanamente ${ }^{48}$, sino de una ética a favor de la justicia, de la práctica de la justicia ${ }^{49}$. Según Raúl Fornet-Betancourt, de esto precisamente se trata el programa de la humanitas, y quizá así sea, si consideramos la triple definición de humanismo de Todorov, que se constituye relacionalmente desde un yo, un tú y un ellos: "Yo debo ser la fuente de mi acción, tú debes ser su objetivo, ellos pertenecen todos a la misma especie humana. Estas tres características [...] no siempre se encuentran juntas [...], pero sólo la reunión de las tres constituye verdaderamente el pensamiento humanista ${ }^{50}$. Desde aquí, el a priori antropológico pone énfasis ya no tanto en la formalidad de los juicios sintéticos a priori, que quieren delimitar el campo del conocimiento ${ }^{51}$, sino en el sujeto juzgante, y con él, a su realidad histórica, que lo pone como valioso para evaluar la propia organización del pensamiento, desde una orientación socio-histórica.

Entonces, volvemos a la humanitas y planteamos este concepto en la línea de la tradición filosófica de un humanismo crítico-ético, para referirnos a una subjetividad concreta, que vive y se funda como existencia comunitaria, alimentada por la memoria de esa lucha de la humanidad negada ${ }^{52}$. En la actualidad, la defensa por el reconocimiento de los indios que diera Bartolomé de las Casas en pleno momento de Conquista, se ha vuelto un concepto de amplio estudio y debate. A veces como una «lucha» ideológica, pero generalmente como una propuesta meramente

45 Cfr. en Fornet-Betancourt, R. (2003), Resistencia y solidaridad. Globalización capitalista y liberación, Trotta, Madrid, pp. 55 y ss.

46 Roig, A. (2009), Teoría y Crítica del pensamiento latinoamericano, Una Ventana, Buenos Aires, p. 17.

${ }_{47} C f r$. Contardi, A., "Aportes de Arturo Roig para una teoría crítica del humanismo», Cuadernos del Pensamiento Latinoamericano, $\mathrm{N}^{\circ} 19$, p. 8.

48 SARTre, J. P. (1982), El ser y la nada, en Obras completas III, Madrid, pp. 103 y ss.

49 Fornet-Betancourt, Resistencia..., op.cit., p. 59

50 Todorov, T. (1999), El jardín imperfecto. Luces y sombras del pensamiento humanista, Paidós, Barcelona, p. 54.

51 Cfr. Kant, I. (2006), Crítica de la razón pura, Taurus, México.

52 Cfr. en: Fornet-Betancourt, R. (2001), Transformación Intercultural de la Filosofía, Desclée de Brouwer, Bilbao. 
formal al interior de las políticas de los diversos Gobiernos del mundo. Por tanto, podemos suponer que el concepto de reconocimiento es objeto de discusión porque contiene variados intereses que soportar, pero seguramente es polémico en cuanto se ha querido identificar como una formulación histórica, concreta, pero no abierta a la realidad. Esto es, a la realidad histórica ${ }^{53}$, que en juego de praxis y teorías van posibilitando una traducción de los diversos modos de realidad.

Desde aquí, quisiéramos resaltar la exposición que Raúl Fornet-Betancourt realizara en la Universidad Católica de Temuco, en Chile, el año 2009, para la inauguración de la Cátedra Bartolomé de Las Casas, titulada «La filosofía intercultural y la Dinámica del Reconocimiento». En dicha ocasión, propone trocar la idea de Reconocimiento por la de Dinámica de Reconocimiento. En la construcción de esta idea, expresa que no se trata, por cierto, de una tarea puramente cognitiva, sino también de una disposición práctica, que se realiza o no en la vida cotidiana — quizá siguiendo al propio Bartolome- ${ }^{54}$. En esta oportunidad agregó que esta cuestión es compleja cuando se quiere considerar el reconocimiento como un proceso abierto, y por ello lanzado a tan diversas posibilidades como logros y derrotas puedan existir; pero sobre todo, cuando es posible registrar contradicciones entre las teorías y las prácticas cotidianas. Es por eso que este filósofo refrenda el hecho de que toda reflexión sobre estas dinámicas de reconocimiento se desarrolla en un contexto conflictual, aún más cuando hablar hoy de reconocimiento versa sobre todo de un problema de desigualdad, y quien habla de desigualdad habla de conflicto e injusticia ${ }^{55}$. Esta posición es relevante en la filosofía de Raúl Fornet-Betancourt, y lo mismo encontramos, por ejemplo, en la filosofía de Ignacio Ellacuría, pues se trataría de un programa transformativo, que no quiere quedar en la crítica de una «lucha por el reconocimiento», por parte de una memoria hegemónica, sino en un movimiento reconstructivo desde las víctimas $^{56}$, esto es, en palabras de Ellacuría, la reconstrucción de la filosofía del reconocimiento desde esos «lugares-que-dan-verdad» ${ }^{57}$.

Desde aquí, podríamos realizar una vuelta a nuestro autor, y ver cómo el pensamiento de Las Casas se vuelve relevante como aportación desde el propio lugar. En efecto, la filosofía tradicionalmente ha persistido en una postura universal y neutra, que es capaz de ponerse en el lugar de cualquier objetivo, pero creemos que esa cuestión, utópica, ha terminado universalizando una filosofía que es filosofía regional. Desde esta situación — problemática-, es que creemos no ha habido respuesta suficiente para superar la historia de conflictos en gran parte del «universo», lo que da cuenta no tan sólo de que las fórmulas esbozadas no han sido suficientes, sino que éstas, muy probablemente, sean parte del mismo problema que nos desafía: Somos parte de una historia en la que esa desigualdad o injusticia no se narra como consecuencia histórica o accidental, sino como referencia fundamental para decidir

53 Ellacuría, I. (1991), Filosofía de la Realidad Histórica, Editorial Trotta y Fundación Xavier Zubiri, Madrid.

54 Cfr. Fornet-Betancourt, R., Transformación intercultural de la filosofía, op.cit., p. 9.

55 Cfr. Ibidem., pp. 11 y ss.

$56 \quad$ Cfr. Ibidem., p. 16.

57 Ellacuría, I. (1985), «Función liberadora de la filosofía», Revista Estudios Centroamericanos (ECA), n 435-436, UCA editores, San Salvador, p. 60 
la normalidad y la normatividad en lo humano; de ahí es que las exigencias del reconocimiento se vean incluso como un avance «espectacular»; de ahí que volver a De las Casas se vuelve fundamental. Sobre esto, Fornet-Betancourt comenta:

«Espectacular es, o debería ser, pues, la patología de una historia cultural y social que ha normalizado teorías y prácticas de negación y de opresión del otro. Esta es la historia a cuya luz deben examinarse las posibilidades y límites de las teorías y las políticas del reconocimiento, para plantear desde esa contextualización histórica la pregunta incómoda de si la respuesta del reconocimiento paga tributo todavía a dicha historia» ${ }^{58}$.

Desde aquí, se puede comprender la necesidad de trocar el concepto de reconocimiento por «dinámica del reconocimiento». Esto se puede fundamentar desde la versión ellacuriana de praxis que el mismo Fornet rescata en la Transformación Intercultural de la filosofía. En él no sólo concede que el objeto de la filosofía es la Realidad Histórica, principio de realidad y de verdad en grado supremo, sino que la praxis histórica es ese dinamismo de realidad que la va posibilitando. Así como lo explica Ignacio Ellacuría en Filosofía de la Realidad Histórica, la realidad histórica es principio de realidad en cuanto en ella se da un summum de realidad; y es principio de verdad, porque en ella podemos ver todas las cosas, o todas las cosas se pueden mostrar con su auténtica veracidad; es decir: tanto por ser aquel más como porque la historización de la teoría muestra su grado de verdad y de realidad. Pero más importante aún, es que la praxis histórica va permanentemente formulando estas «verdades», cuestiones nuevas, en cuanto éstas son cuestiones vivas, siempre en desarrollo, y hacen creativo el pensamiento; aunque - agrega - siempre que éste se deje incitar por las realidades que deben ser conocidas y transformadas ${ }^{59}$. De esta forma, la praxis histórica es una praxis liberadora, adquiere un importante compromiso ético y da un sentido más pleno a la filosofía, como a todo pensamiento.

Así bien, podemos recalcar una cuestión que parece relevante en el marco de este trabajo, pues, aún cuando en La Colonia las esperanzas de vida (o de sobrevivencia) fueran prácticamente nulas para los nativos de América, hubo quienes no vieron ahí solo desesperanza, sino desafíos nuevos, en el marco de una apertura al propio concepto de Humanismo, que los caracterizaba. Pero al margen de lo que podríamos considerar incluso objetivo del giro antropológico de aquel momento, hay que destacar una interesante mixtura entre estos desafíos modernos y los de la propia fe cristiana.

En efecto, allí donde Bartolomé halló vida y humanidad, desde un profetismo evangélico —inspirado en la imagen de Jesús de Nazareth-, hoy podemos decir hay sujetos vivos, contra todo pronóstico de mortandad. La interculturalidad quiere hoy día rescatar al sujeto vivo, con alma — con «espíritu ${ }^{60}$, diría Ellacuría—. Pues, aquellas comunidades precolombinas, como los humillados de hoy, no

58 Fornet-Betancourt, R., Transformación intercultural de la filosofía, op.cit. p. 14.

59 Ellacuría, I. (1985), «Función liberadora de la filosofía», Revista Estudios Centroamericanos (ECA), $\mathrm{n}^{\circ}$ 435-436, UCA editores, San Salvador, p. 112

60 Ellacuría, I. (1990), «Utopía y profetismo desde América Latina; un ensayo concreto de soteriología histórica», en Ellacuría, I. - Sobrino, J., (Comps.) Mysterium Liberationis, Tomo 1, Editorial Trotta - Fundación Xavier Zubiri, Madrid, p. 412. 
necesitaban ni necesitan que la filosofía - o la teología - o la ciencia, les digan qué son, pues saben que son sujetos en su práctica cotidiana, en su experiencia de sujetos, implicados con la realidad; desde una vivencia biológica y social, con la que están siendo sujetos en la forma de sus ocupaciones y preocupaciones, de sus complicaciones ${ }^{61}$.

Sí, no es lo mismo proponer una tesis sobre el reconocimiento entre hombres «enfermos» o muertos, que otra entre hombres vivos y capaces. Estos últimos son sin duda los sujetos de la historia para la Interculturalidad. Por lo tanto, que se haya diagnosticado la muerte o cierta enfermedad del sujeto, en el sentido de «quitarle firmeza» —en la versión etimológica de la palabra enfermedad — al "yo», en otro momento importante de nuestra historia, se cree que no es, sino, para construirle como empresario de su propia vida, en la más famosa versión de emprendimiento solipsista que caracterizaría nuestros sistemas. Así pues, el sujeto vivo no es el héroe (que sobresale por sí solo), sino todo lo contrario; en su mayoría, el sujeto es el que aunque se ha mantenido invisibilizado, sigue vivo, y lo es en cuanto es capaz, aún, de escribir su biografía en comunidad y en solidaridad. El sujeto vivo es un sujeto cotidiano, que no lucha por su supervivencia —en palabras de Fornet-Betancourt - "porque está preocupado por su vida como con-vivencia de todos ${ }^{62}$.

Con todo, se puede ver que la interculturalidad así entendida es una teoría de la disposición $^{63}$. Esto es, por lo menos, disposición a escuchar y a aprender; a darse a entender, con contenidos veraces; por lo tanto, una filosofía abierta y procesual, en cuanto sea capaz de reconocer sus propias discordancias, y fecundarse en la misma praxis. Desde aquí, la filósofa Diana de Vallescar sugiere tres ejes vertebradores de la filosofía intercultural: "(a) el pluralismo y la pluralidad de la filosofía, (b) el diálogo, (c) la razón contextual» ${ }^{64}$.

En el primero se instaura la necesidad de contribuir a una filosofía nueva, dado el contexto plural que es dato experiencial. Por tanto, se presenta la necesidad de liberar a la filosofía, y dirigirla hacia filosofías contextuales, donde quepan figuras como «el bárbaro, el pagano, el no-cristiano, el extranjero, el no-ciudadano, el inmigrante, el indígena, la mujer, etc., todas ellas distantes, ajenas, excéntricas, fronterizas y extrañas ${ }^{65}$. Todas ellas, figuras contemporáneamente visibles, aunque sorpresivas; y por tanto, con un impacto que afecta a las teorías — como alguna vez pasmaron a los Conquistadores-; de tal modo que hoy — como ayer- representan un claro conflicto para la sociedad. Esta pluralidad que hoy se presenta como desafío de la multiculturalidad en la mayoría de las sociedades, puede entenderse como la conciencia del otro y de lo otro: aliud et alius, una conciencia histórica fundada en una convicción que Panikkar resalta muy bien: «la conciencia de que yo (mi razón, mi conciencia, mi ser) no agoto lo real, no soy su centro — de ser

61 Fornet-Betancourt, R., Transformación intercultural de la filosofía, op.cit., p. 365.

62 Ibídem., p. 368.

63 Fornet-Betancourt, R. (2009), Tareas y Propuestas de la filosofía Intercultural, Concordia, serie Monografías, tomo 49, Aachen.

64 De Vallescar, D. (2001), «Coordenadas de la Interculturalidad», en Diálogo Filosófico, núm. 51, p. 391.

65 Ibidem., p. 401. 
algo, tan sólo soy uno de sus polos-. - Pues- hay otra cosa: aliud, lo otro. Y esto no sólo además de mí y del yo, sino que también, frente a ello e incluso más allá de ello» ${ }^{66}$. Desde aquí, como sabemos, no hay yo sin un otro; empero, como hemos podido corroborar históricamente, esos han sido los motivos para deslegitimar la presencia de un otro como yo.

En el segundo eje encontramos al diálogo, articulador de nuestras propias certezas, dentro de una dinámica relacional que involucra nuestras convicciones y las que otros tienen sobre nosotros (y viceversa). Desde aquí se entiende la necesidad filosófica de pensar el acceso al otro, de conocer al cognoscente, y en última instancia, de preguntarnos por la naturaleza del conocimiento, y por tanto, por nuevas herramientas hermenéuticas ${ }^{67}$. Se trataría de una hermenéutica diaptópica, que enfatice la importancia de la interpretación de cada cultura, de cada lugar (topoi), con todas las características que subyacen en las narraciones de unos y otros. Esta idea, original de Panikkar, y que podemos leer largamente en el libro de Fornet, Crítica intercultural de la filosofía latinoamericana, viene a presentar el diálogo como un momento del inter, el que se puede dar de dos modalidades: como diálogo dialógico o como diálogo dialéctico. El primero da cuenta de dos (o más) interlocutores válidos que les interesa participar; en el sentido de valorar a la otra persona como digna de conocer, y con ella autocomprenderse; para esto se requiere un mínimo de reconocimiento y respeto por una estructura interna que rige eso que dicen. Esa estructura, al fin, no es un medidor externo, sino parte de ellos mismos, y de su peculiar intencionalidad dialógica ${ }^{68}$. El segundo diálogo se refiere a los objetos que interesan a los interlocutores, y por lo tanto que los sumerge racionalmente en un diálogo en el que se quiere persuadir con los distintos puntos de vistas al otro, so pena de caer derrotado. Pero aquí habrá que reconocer que la negación del uso de la razón haría imposible todo diálogo. Y en cuanto a estos diálogos, mostrar que el segundo es más común que el primero, lo que dificulta la comprensión al otro desde estos momentos. Desde aquí, habrá que subrayar la dificultad para que el intercambio entre distintas culturas se dé con simetría o simplemente se dé.

En el tercer eje encontramos la razón contextual, donde se viene a explicitar que no existe la neutralidad, y por lo tanto que en todo paradigma no sólo las respuestas sino también las preguntas y problemas pertenecen a contextos. Contextos, escrito en plural, dada la crítica a la universalidad que subraya la interculturalidad; es decir, una crítica a la universalidad (occidental), "como resultado de una autoproclamación y extensión monocultural» ${ }^{69}$. Según Fornet-Betancourt, la pluralidad de razones viene a mostrar, en el contraste de todas ellas, figuras inéditas de la razón; racionalidades vistas desde la racionalidad dominante-universalizada como no-racionales ${ }^{70}$. Así bien, la filosofía interculturalidad sería aquella disposición a «ensanchar las racionalidades» ${ }^{71}$, a abrirse a la posibilidad de que

\footnotetext{
66 Panikkar, R. (1990), Sobre el diálogo intercultural, Salamanca, p. 401.

67 De Vallescar, D., «Coordenadas de la Interculturalidad», op.cit., p. 402.

68 Ibidem., p. 404.

69 Fornet-Betancourt, R. (1990), «Filosofía Latinoamericana ¿Posibilidad o realidad?», en Logos. Revista de Filosofía, México, Universidad de La Salle, p. 406.

70 Cfr. Ibidem., p. 54.

71 Entrevista a Fornet Betaconcourt, en Oviedo García, A. (2006). Raúl Fornet-Betancourt, La fecundidad de la filosofía latinoamericana, Utopía y Praxis Latinoamericana, Maracaibo, v. 11, n. 34.
} 
haya otros tipos de razón. Éste es un paso difícil y controvertido, sobre todo porque — como este mismo autor dice, siguiendo a Panikkar- estamos "acostumbrados ${ }^{72}$ a que la razón clasifique y ordene el conocimiento, y a dar por supuesto que conocimiento significa clasificar, definir y ordenar, como consecuencia de un orden lógico occidental. De ahí la dificultad. Pues el paso a la interculturalidad consiste precisamente en ver cómo desde una cierta "polifonía» de voces, se llega a un nivel de comunicación verdaderamente plural, esto es, basado no sólo en "voces» entendidas como declinaciones de una misma razón (o Ley Natural, — para el siglo XVI-), sino en formas diversas de «razón»—o de Leyes—. Desde aquí, FornetBetancourt comenta:

«Lo que ya aquí se pone en cuestión no sólo es el esquema occidental sujetoobjeto, del sujeto cognoscente que va a cazar al objeto, que va a definirlo, que va a clasificarlo, sino que lo que se está poniendo en cuestión es toda una concepción de la verdad, de lo real y de lo humano que nos ha llevado a leer toda la historia desde la clave de la dialéctica entre lo universal y lo particular. Por este cuestionamiento vemos que otra perspectiva es posible, a saber, la siguiente: no hay universal ni hay particular, hay universos; hay una pluralidad de universos. Y que en esa pluralidad de universos tenemos una pluralidad de razones ${ }^{73}$.

\section{Conclusiones}

Como hemos expuesto en un comienzo, en el pensamiento de Bartolomé de Las Casas es posible hallar importantes cimientos para lo que aquí se ha esbozado. No estamos, por supuesto, ante un defensor de una pluralidad de racionalidades, ni tampoco de un detractor de ciertos dogmas, que presenta, por cierto, como premisas mayores; empero, sí vemos en Bartolomé de las Casas un defensor de la humanidad, y del reconocimiento de una pluralidad de formas de razón, que al alero del siglo XVI, se vuelve un discurso revolucionario. Quizá, De las Casas fue el primero en reconocer al irrefutablemente otro en su más absoluta alteridad, pero a pesar de los siglos que le han superado, la superación de la pretendida humanización que quiere consolidar la emancipación del ser humano, y la aceptación de una multiculturalidad, todavía se vuelve un desafío para el propio ser humano. Pues es cierto, cinco siglos después aún hay necesidad de aquel reconocimiento por el que nuestro autor luchó, y por el que aún no sabemos cómo reaccionar. Comunidades hoy, aún, "pillan» a las filosofías sin respuestas, y lo que es peor, (la mayor de las veces) sin preguntas.

Desde aquí, Bartolomé de las Casas se vuelve actual, necesario, sobre todo porque nos aproxima a esas nuevas discusiones sobre el reconocimiento que ha querido proponer la filosofía intercultural. Esta, creemos, nos permitiría situarnos en una disposición de reconocer cualquier (otro) «inter» que nos pueda sorprender.

72 PanikKar, R., Sobre el diálogo intercultural, op. cit., p. 90.

73 Entrevista a Fornet Betaconcourt, op. cit. 


\section{BibliograFÍA}

Abril Castelló, V. (1984), «La bipolarización Sepúlveda-Las Casas y sus consecuencias: la revolución de la duodécima réplica», en Ramos, D., La ética en la conquista de América. Francisco de Vitoria y la Escuela de Salamanca. Madrid: Consejo Superior de Investigaciones científicas, pp.229-288.

Abril Castelló, V. (1992), "Los derechos de las naciones según Bartolomé de Las Casas y la Escuela de Salamanca», en De Las Casas, Bartolomé, Obras completas, t. 6, Apologética historia sumaria 1, Madrid.

Aristóteles, Política, lib. I 2, 18 (1255 a), lib.. I 2,13 (1254 b).

ARistoteles, Tópicos, lib. 1, 1 (100b).

Bataillon, M. (1966), Erasmo y España, trad. de A. Alatorre, México, pp. 704-720.

Breen, Q. (1952), «Giovanni Pico de la Mirandola on the Conflict of Philosophy and Rhetoric», Journal of the History of Ideas, Vol. 13, No. 3, pp. 384-412.

Contardi, A., "Aportes de Arturo Roig para una teoría crítica del humanismo», Cuadernos del Pensamiento Latinoamericano, $\mathrm{N}^{\circ} 19$, pp.1-16.

De Aquino, Tomás, Questiones disputatae. De veritate, q. 16, art. 1, http://www.corpusthomis ticum.org/qdv15.html. [Revisado en junio de 2015].

De la Hoz, J. C. M. (2007), «Bartolomé de Las Casas y la «captatio benevolentiae», Ciencia tomista, t. 134, núm. 433.

De Las Casas, B., Apologética historia sumaria, lib. III, cap. 40, Fundación el Libro Total, en: http://www.ellibrototal.com/ltotal/?t=1\&d=4072_4167_1_1_4072. [Revisado en junio de 2015

De las Casas, B. (1992), Controversia entre Las Casas y Sepúlveda, en Obras completas 10: Tratados de 1552, ed. Hernández. R. y Galmés, L., Madrid.

De LAS CASAS, B. (1975), Del único modo de atraer a todos los pueblos a la verdadera religión, advertencia preliminar de A. Millanes Carlo, introd. de Hanke, L., México.

De Montaigne, M., De los caníbales, en: idem, Ensayos, ed. digital: http://bib.cervantesvirtual. com/servlet/SirveObras/01372719700248615644802/p0000002.htm\#I_36_. [Revisado en junio de 2015].

De RotTerdam, E., Ratio verae theologiae, LB 99 a, H 225.

De Vallescar, D. (2001), «Coordenadas de la Interculturalidad», en Diálogo Filosófico, núm. $51, \mathrm{pp} .386-410$.

De Vitoria, F. (1992), Doctrina sobre los indios, ed. de Ramón Hernández, Salamanca.

EllacuRía, I. (1985), «Función liberadora de la filosofía», Revista Estudios Centroamericanos (ECA), $\mathrm{n}^{\circ}$ 435-436, UCA editores, San Salvador.

EllacuRía, I. (1990), «Utopía y profetismo desde América Latina; un ensayo concreto de soteriología histórica», en Ellacuría, I. - Sobrino, J., (Comps.) Mysterium Liberationis, Tomo 1, Editorial Trotta - Fundación Xavier Zubiri, Madrid.

Ellacuría, I. (1991), Filosofía de la Realidad Histórica, Editorial Trotta y Fundación Xavier Zubiri, Madrid.

Fernández Buey, F., «La controversia entre Ginés de Sepúlveda y Bartolomé de Las Casas. Una revisión», Boletín Americanista 1992-1993, núm. 42-43, pp. 301-347.

Fornet-Betancourt, R. (1990), «Filosofía Latinoamericana ¿Posibilidad o realidad?», en Logos. Revista de Filosofía, México, Universidad de La Salle.

Fornet-Betancourt, R. (2003), Interculturalidad y Filosofía en América Latina, Verlag Mainz (Concordia, serie Monográfica, 36), Aachen.

Fornet-Betancourt, R. (2001), Transformación Intercultural de la Filosofía, Desclée de Brouwer, Bilbao.

Fornet-BETANCOURT, R. (2003), Resistencia y solidaridad. Globalización capitalista y liberación, Trotta, Madrid.

Fornet-Betancourt, R. (2009), Tareas y Propuestas de la filosofía Intercultural, Concordia, serie Monografías, tomo 49, Aachen. 
FrIede, J. (1974), Bartolomé de Las Casas, precursor del anticolonialismo. Su lucha y su derrota, Siglo XXI, México.

Ginés de SePúlvedA, J. (1997), «Demócrates segundo», en Obras completas III, Pozo Blanco.

Kant, I. (2006), Crítica de la razón pura, Taurus, México.

Nauert, $\mathrm{CH}_{\text {., }}$ "Humanism as Method: Roots of Conflict with the Scholastics», The Sixteenth Century Journal 1998, Vol. 29, No. 2, pp. 427-438.

O’ Gorman, E. (1958), La invención de América. El Universalismo de la Cultura de Occidente, México-Buenos Aires.

Oviedo García, A., (2006)Raúl Fornet-Betancourt, La fecundidad de la filosofía latinoamericana, Utopía y Praxis Latinoamericana, Maracaibo, v. 11, n. 34.

PanikKar, R. (2006), Paz e Interculturalidad. Una reflexión filosófica, Herder, Milán.

PanikKar, R. (1990), Sobre el diálogo intercultural, Salamanca.

Perreiah, A. (1982), "Humanistic Critiques of Scholastic Dialectic», The Sixteenth Century Journal, Vol. 13, No. 3, pp. 3-22.

Rengifo Lozano, B. (2007), Naturaleza y etnocidio, Bogotá, pp. 48-66.

Roig, A. (2009), Teoría y Crítica del pensamiento latinoamericano, Una Ventana, Buenos Aires.

Rummel, E. (1992), «Et cum theologo bella poeta gerit. The Conflict between Humanists and Scholastics Revisited», The Sixteenth Century Journal, Vol. 23, No. 2, pp. 713-726.

SARTRe, JEAN P. (1982), El ser y la nada, en Obras completas III, Madrid.

Sснмттт, Сн. B. (1966), «Perennial Philosophy: From Agostino Steuco to Leibniz», Jourmal of the History of Ideas, Vol. 27, No. 4, pp. 505-532.

Someda, H. (2005), Apología e historia. Estudios sobre fray Bartolomé de Las Casas, Editorial de la Pontificia Universidad Católica de Perú, Lima, pp. 40-45.

SwIEżawsKi, S. (2002), Między średniowieczem a czasami nowymi. Sylwetki myślicieli XV wieku, Biblioteka Wiezi, Warszawa.

Todorov, T. (1998), La conquista de América. El problema del Otro, México.

Todorov, T. (1999), El jardín imperfecto. Luces y sombras del pensamiento humanista, Paidós, Barcelona.

Zabala, S. (1994), Filosofía de la Conquista, México, FCE.

Zavala, S. (1975), Servidumbre natural y libertad cristiana según los tratadistas españoles de los siglos XVI y XVII, ed. 2, México.

Universidad Técnica Federico Santa María, Chile

Departamento de Estudios Humanísticos

lorena.zuchel@usm.cl

Universidad de Gdańsk, Polonia

Departamento de Historia de la Filosofía Moderna

IWONA KRUPECKA

ikrupecka@wp.pl

[Artículo aprobado para publicación en diciembre de 2015] 
